\title{
A Prospective Study on Mortality among Japanese Coal Miners
}

\author{
Hiroshi UNE ${ }^{\text {a) }}$, Hiroji ESAKI ${ }^{\text {a) }}$, Kenichi OSAJIMA ${ }^{\text {a) }}$ \\ Haruhiko IKUI $^{\text {a) }}$, Kayo KODAMA ${ }^{\text {b) }}$ and Kazunori HATADA ${ }^{\text {c) }}$
}

\author{
a) Department of Hygiene, School of Medicine, Fukuoka University, \\ Fukuoka 814-80, Japan \\ b) Iizuka Health Center, Fukuoka 820, Japan \\ c) Tagawa Health Center, Fukuoka 825, Japan
}

(Received February 1, 1995 and in revised form July 13, 1995)

\begin{abstract}
We conducted a prospective study to clarify mortality patterns among Japanese coal miners in a former coal mining area. Subjects included 1,796 coal miners and 4,022 non-coal-miners, who were identified by a mail survey between 1987 and 1989, and then followed up from the date of the survey to April 30th, 1994. We applied Cox's proportional hazards model to compare the mortalities between coal miners and non-coalminers. Among the coal miners, significantly high risk ratios were observed in all causes of death (risk ratio $=1.4, p<0.05$ ) and all malignant neoplasms (risk ratio $=1.5$, $p<$ 0.05). Risk ratios for all causes of death and all malignant neoplasms also rose with the length of experience in coal mining. Analysis of the results for sites of cancer showed that coal miners had high risk ratios for stomach cancer (risk ratio $=1.6$ ), liver cancer (risk ratio $=1.4)$ and lung cancer (risk ratio $=1.6)$, though these ratios were not statistically significant. When the risk ratio for lung cancer was analyzed according to the length of experience in coal mining, coal miners with at least 15 years' experience had a significantly high risk ratio (risk ratio $=2.4, p<0.05$ ), though coal miners with less than 15 years' experience had almost the same risk as non-coal-miners.
\end{abstract}

Key words: Mortality — Epidemiological Study — Coal Miners — Pneumoconiosis

\section{INTRODUCTION}

There have been many epidemiological studies on mortality among silicosis patients and workers exposed to dust, especially silica ${ }^{1-13)}$. In these studies, particular attention has been paid to the association between dust exposure and cancer. Many studies have demonstrated that silicosis patients and workers exposed to dust have a high risk of lung cancer ${ }^{1-12}$. It has been suggested that exposure to dust 
may be associated not only with lung cancer but also with other cancers ${ }^{1-3)}$. There have been a few epidemiological studies in Japan on cancer mortality among pneumoconiosis patients and workers exposed to dust ${ }^{1,4-6)}$. These studies showed that exposure to dust was associated with lung cancer : relative to male Japanese in general, risks of lung cancer were raised 2.1-fold among ceramic workers with pneumoconiosis ${ }^{4}$, 2.9-fold among copper miners ${ }^{5}$, and 3.2 and 4.2-fold among pneumoconiosis patients ${ }^{1,6)}$. Although smoking has been found to be a much more important risk factor for lung cancer than exposure to dust, these studies did not take the effect of smoking into account. Moreover, because they used national mortality rates as a standard in estimating the risk of lung cancer, they failed to take account of geographical variations in mortality, which may also affect risk. Our study of mortality, especially cancer mortality, among Japanese coal miners was designed to take these two points into consideration.

Japanese coal miners are exposed to relatively high concentrations of silica dust because most Japanese coal mines have thin coal seams. Therefore, they tend to suffer from silicosis ${ }^{13)}$. Although the Japanese coal industry has been decline since around 1960, with the number of active coal miners falling sharply every year, there are still many former coal miners who have silicosis. In addition, a number of workers are exposed to silica dust in certain other industries. Therefore, an epidemiological study on mortality among coal miners remains of importance and of special interest.

\section{Materials ANd Methods}

We selected three towns in a former coal mining area in Japan for an epidemiological study on mortality among coal miners. All coal mines in this area were shut down by 1973 because of the decline of the coal industry. The male population aged 40-69 in the three towns was 9,943. These males were identified from the municipal population registers. We mailed questionnaires to them during 19871989, obtaining information on their medical histories, smoking habits, drinking habits and occupational histories, especially any history of coal mining work. Of the 9,943 men, $5,818(58.5 \%)$ responded to the questionnaire. We classified respondents into two groups according to whether they had worked as coal miners. These groups are referred to hereafter as the 'coal miner' and 'non-coal-miner' groups, respectively. Table 1 shows the age distribution of coal miners and noncoal-miners at the start of the follow-up period. Coal miners were, on average, older than non-coal-miners. Table 2 shows the distribution in years of experience in coal mining among 1,796 coal miners. The mean was $14.3 \pm 9.8$ years (mean $\pm \mathrm{SD})$.

The follow-up period extended from the date of the mail survey to April 30th, 1994. Emigrants were identified through the municipal population registers. We identified all cases of deaths from death certificates. During the follow-up pe- 
Table 1. Age distributions of coal miners and non-coal-miners

\begin{tabular}{ccc}
\hline Age & Coal miners & Non-coal-miners \\
\hline $40-49$ & 122 & 1,652 \\
$50-59$ & 595 & 1,344 \\
$60-69$ & 1,079 & 1,026 \\
\hline Total & 1,796 & 4,022 \\
\hline
\end{tabular}

Table 2. Years of experience in coal mining

\begin{tabular}{ccc}
\hline Years & Number & $(\%)$ \\
\hline $1-4$ & 327 & $(18.2)$ \\
$5-9$ & 329 & $(18.3)$ \\
$10-14$ & 329 & $(18.3)$ \\
$15-19$ & 275 & $(15.3)$ \\
$20-24$ & 197 & $(11.0)$ \\
$25+$ & 339 & $(18.9)$ \\
\hline Total & 1,796 & $(100)$ \\
\hline
\end{tabular}

riod, 169 of the coal miners and 168 of the non-coal-miners died. Causes of death were coded according to the 9th revision of the International Classification of Diseases (ICD).

Standardized mortality ratios (SMRs) were calculated, using 1991 age-causespecific mortality rates for Japanese males. The observed periods were $8,834.5$ person-years for coal miners and 19,241.3 person-years for non-coal-miners. Statistical significance was assessed by comparison with the Poisson distribution if the expected number of deaths was less than five and with the chi-square distribution if it was five or more.

We applied Cox's proportional hazards model to compare the mortalities between coal miners and non-coal-miners; risk ratios were then estimated for selected causes of death among coal miners, adjusted for age, smoking habits and other factors. We also divided coal miners into two groups according to how long individuals had worked as coal miners, and estimated risk ratios for each group. The SAS statistical package was used for data analysis.

\section{RESULTS}

1. Standardized mortality ratios for selected causes of death

Table 3 shows SMRs for selected causes of death among coal miners and noncoal-miners. Among coal miners, the overall SMR was 120 , which was statisti- 
Table 3. Standardized mortality ratios for selected causes of death

\begin{tabular}{|c|c|c|c|c|c|c|c|}
\hline \multirow[t]{2}{*}{ Causes of death } & \multirow[t]{2}{*}{ ICD } & \multicolumn{3}{|c|}{ Coal miners } & \multicolumn{3}{|c|}{ Non-coal-miners } \\
\hline & & Obs. & Exp. & SMRs & Obs. & Exp. & SMRs \\
\hline All causes & & 169 & 140.9 & $120 *$ & 168 & 181.1 & 93 \\
\hline Tuberculosis & $010-018$ & 2 & 0.8 & 244 & 0 & 1.1 & 0 \\
\hline All malignant neoplasms & $140-208$ & 88 & 58.6 & $150 * * *$ & 75 & 72.9 & 103 \\
\hline Stomach & 151 & 13 & 12.4 & 105 & 9 & 15.6 & 58 \\
\hline Colon \& Rectum & $153-154$ & 6 & 6.3 & 95 & 10 & 8.0 & 125 \\
\hline Liver & 155 & 25 & 9.4 & $266^{* * *}$ & 25 & 12.5 & $200 * * *$ \\
\hline Pancreas & 157 & 4 & 3.3 & 123 & 1 & 4.1 & 24 \\
\hline Lung & 162 & 19 & 12.5 & 152 & 13 & 14.2 & 92 \\
\hline Heart diseases & $393-398,410-429$ & 22 & 22.8 & 96 & 20 & 28.7 & 70 \\
\hline Ischemic heart diseases & $410-414$ & 5 & 8.4 & 60 & 7 & 10.2 & 69 \\
\hline Cerebrovascular diseases & $430-438$ & 7 & 14.7 & 48 & 22 & 18.7 & 118 \\
\hline Pneumonia & $480-487$ & 10 & 8.0 & 125 & 6 & 8.5 & 71 \\
\hline $\begin{array}{l}\text { Bronchitis, emphysema and } \\
\text { asthma }\end{array}$ & $490-496$ & 1 & 2.2 & 45 & 2 & 2.3 & 88 \\
\hline Pneumoconiosis & $500-508$ & 9 & I & l & l & l & I \\
\hline External causes & E800-999 & 17 & 9.1 & $187 * *$ & 17 & 16.5 & 103 \\
\hline
\end{tabular}

cally significant $(\mathrm{p}<0.05)$. Statistical significance was observed for all malignant neoplasms (SMR=150, p < 0.001), liver cancer $(\mathrm{SMR}=266, \mathrm{p}<0.001)$, and external causes $(\mathrm{SMR}=187, \mathrm{p}<0.01)$. There were 9 deaths from pneumoconiosis. Among non-coal-miners, the overall SMR was 95. Statistical significance was observed only for liver cancer $(S M R=200, p<0.001)$.

\section{Risk ratios for selected causes of death among coal miners}

Table 4 shows risk ratios for selected causes of death among coal miners. As shown in Table 4, these risk ratios were adjusted for possible confounding factors such as age, smoking habits, drinking habits, and blood transfusion. Table 5 shows smoking habits and drinking habits among coal miners and non-coal-miners. Significantly high risk ratios were observed for all causes of death (risk ratio = $1.4, \mathrm{p}<0.01$ ) and for all malignant neoplasms (risk ratio $=1.5, \mathrm{p}<0.05$ ). Risk ratios for selected sites of cancer showed that coal miners had higher risk of stomach cancer, liver cancer and lung cancer than non-coal-miners, but these results were not statistically significant.

Tables 6-8 show risk ratios for all causes of death, all malignant neoplasms, and lung cancer among coal miners according to their length of experience in 
Table 4. Risk ratios of coal mining for selected causes of death

\begin{tabular}{lccc}
\hline \multicolumn{1}{c}{ Causes of death } & ICD & Risk ratios & $(95 \%$ confidence interval) \\
\hline All causes & & $1.4^{\mathrm{a}}$ & $(1.1-1.7)^{* *}$ \\
All malignarit neoplasms & $140-208$ & $1.5^{\mathrm{a}}$ & $(1.1-2.1)^{*}$ \\
$\quad$ Stomach & 151 & $1.6^{\mathrm{a}}$ & $(0.7-3.8)$ \\
$\quad$ Colon \& rectum & $153-154$ & $0.8^{\mathrm{a}}$ & $(0.3-2.3)$ \\
$\quad$ Liver & 155 & $1.4^{\mathrm{b}}$ & $(0.8-2.5)$ \\
Lung & 162 & $1.6^{\mathrm{a}}$ & $(0.8-3.4)$ \\
Heart diseases & $393-398,410-429$ & $1.7^{\mathrm{a}}$ & $(0.9-3.2)$ \\
$\quad$ Ischemic heart diseases & $410-414$ & $1.0^{\mathrm{a}}$ & $(0.3-3.3)$ \\
Cerebrovascular diseases & $430-438$ & $0.5^{\mathrm{a}}$ & $(0.2-1.2)$ \\
Pneumonia & $480-487$ & $1.7^{\mathrm{a}}$ & $(0.6-4.9)$ \\
External causes & E800-999 & $1.8^{\mathrm{c}}$ & $(0.9-3.7)$ \\
\hline
\end{tabular}

* $\mathrm{p}<0.05 \quad * * \mathrm{p}<0.01$

a: Adjusted for age and smoking habits.

b: Adjusted for age, smoking habits, drinking habits and blood transfusion.

c: Adjusted for age.

Table 5. Cigarette smoking and alcohol drinking among coal miners and non-coalminers

\begin{tabular}{lcr}
\hline Smoking \& Jrinking & Coal miners $(\%)$ & Non-coal-miners (\%) \\
\hline Cigarette smoking & & \\
Non-smokers & $262(14.6)$ & $987(24.5)$ \\
Ex-smokers & $482(26.8)$ & $917(22.8)$ \\
Current smokers & $430(23.9)$ & $603(15.0)$ \\
$1-19^{*}$ & $622(34.6)$ & $1,515(37.7)$ \\
$20+^{*}$ & $1,796(100)$ & $4,022(100)$ \\
Total & & $968(24.1)$ \\
\hline Alcohol drinking & $564(31.4)$ & $905(22.5)$ \\
Non-drink:ers & $354(19.7)$ & $303(7.5)$ \\
Occasional drinkers & & $964(24.0)$ \\
Regular drinkers & $109(6.1)$ & $882(21.9)$ \\
$<27$ g/day & $351(19.5)$ & $4,022(100)$ \\
$27-53$ g/day $\$$ & $418(23.3)$ & \\
$>53$ g/day & $1,796(100)$ & \\
Total & & \\
\hline
\end{tabular}

$¥$ : Number of cigarettes/day

$\$$ : Grams of ethanol/day 
Table 6. Risk ratios of coal mining and other risk factors for all causes of death

\begin{tabular}{lcc}
\hline \multicolumn{1}{c}{ Factors } & Risk ratios & (95\% confidence interval) \\
\hline Age (10 year interval) & 2.0 & $(1.7-2.3)^{* * *}$ \\
Experience in coal mining & & \\
$\quad$ Non-coal-miners & 1.0 & $(0.9-1.6)$ \\
$\quad<15$ years & 1.2 & $(1.2-2.0)^{* *}$ \\
$\quad \geq 15$ years & 1.5 & \\
Cigarette smoking & & \\
Non-smokers & 1.0 & $(0.9-2.0)$ \\
Ex -smokers & 1.4 & $(1.2-2.4)^{* *}$ \\
Current smokers & & $(0.9-1.8)$ \\
$\quad<20$ cigarettes/day & 1.7 & \\
$\geq 20$ cigarettes/day & 1.3 &
\end{tabular}

$* \mathrm{p}<0.05 \quad * * \mathrm{p}<0.01 \quad * * * \mathrm{p}<0.001$

Adjusted for other variables in this table.

Table 7. Risk ratios of coal mining and other risk factors for all malignant neoplasms

\begin{tabular}{lcc}
\hline \multicolumn{1}{c}{ Factors } & Risk ratios & (95\% confidence interval) \\
\hline Age (10 year interval) & 2.2 & $(1.7-2.9)^{* * *}$ \\
Experience in coal mining & & \\
$\quad$ Non-coal-miners & 1.0 & \\
$\quad<15$ years & 1.3 & $(0.9-2.0)$ \\
$\geq 15$ years & 1.6 & $(1.1-2.4)^{*}$ \\
Cigarette smoking & & \\
Non-smokers & 1.0 & \\
Ex-smokers & 3.0 & $(1.5-6.0)^{* *}$ \\
Current smokers & & \\
$<20$ cigarettes/day & 3.6 & $(1.8-7.2)^{* * *}$ \\
$\geq 20$ cigarettes/day & 3.6 & $(1.8-7.0)^{* * *}$ \\
\hline ** $\mathrm{p}<0.01 \quad * * * \mathrm{p}<0.001$ & &
\end{tabular}

* $\mathrm{p}<0.05 \quad * * \mathrm{p}<0.01 \quad * * * \mathrm{p}<0.001$

Adjusted for other variables in this table.

coal mining. In these analyses, age, smoking habits and experience in coal mining were included as independent variables. Risk ratios for all causes of death were 1.2 for coal miners with less than 15 years' experience (hereafter short experience) and 1.5 for those with at least 15 years' experience (hereafter long experience) $(p<0.01)$. Risk ratios for all malignant neoplasms also increased with the length of experience in coal mining, at 1.3 for coal miners with short experience and 1.6 for those with long experience $(\mathrm{p}<0.05)$. Risk ratios for lung 
Table 8. Risk ratios of coal mining and other risk factors for lung cancer

\begin{tabular}{lcc}
\hline \multicolumn{1}{c}{ Factors } & Risk ratios & (95\% confidence interval) \\
\hline Age (10 year interval) & 3.2 & $(1.6-6.3)^{* * *}$ \\
Experience in coal mining & & \\
$\quad$ Non-coal-miners & 1.0 & \\
$\quad<15$ years & 0.9 & $(0.3-2.6)$ \\
$\quad \geq 15$ years & 2.4 & $(1.1-5.3)^{*}$ \\
Cigarette smoking & & \\
Non-smokers & 1.0 & \\
Ex-smokers & 5.9 & $(0.7-46.1)$ \\
Current smokers & & $(0.6-39.1)$ \\
$\quad<20$ cigarettes/day & 4.7 & $(1.1-64.7)^{*}$ \\
$\quad 20$ cigarettes/day & 8.5 & \\
\hline
\end{tabular}

$* \mathrm{p}<0.05 \quad * * * \mathrm{p}<0.001$

Adjusted for other variables in this table.

cancer were significantly higher among coal miners with long experience (risk ratio $=2.4, \mathrm{p}<0.05)$, but coal miners with short experience had almost the same risk (risk ratio $=0.9$ ) as non-coal-miners.

Coal miners showed significantly higher SMRs for liver cancer and external causes, but risk ratios for these two causes of death revealed no statistical significance when compared with non-coal-miners.

\section{DisCusSion}

There have been many cohort studies on mortality among silicosis patients and workers exposed to dust ${ }^{1-12}$. In many of these studies, estimates of risk were generally based on national age-cause-specific mortality rates 1, 2, 4-6, 8, 12). Mortality patterns vary from area to area, however, so using national data as a standard can lead to biased conclusions. Thus, we did not rely solely on SMRs calculated using all-Japan age-cause-specific mortality rates as a standard; to avoid the effects of geographical variations in mortality, we compared mortality for coal miners and non-coal-miners living in the same area and sharing similar environmental factors.

Coal miners had significantly elevated risk for all causes of death, with their risk ratios for all causes of death rising with length of experience in coal mining. Although length of experience in coal mining is only an indirect index of exposure to dust, all 9 deaths from pneumoconiosis were among coal miners with longer experience, suggesting that this factor does reflect exposure to dust. Chen et $a l .{ }^{12)}$ indicated a dose-response relationship between all causes of death and levels of exposure to dust.

Many epidemiological studies have reported increased risks of lung cancer 
associated with exposure to silica ${ }^{1-11,14}$.15). In our study, coal miners with long experience had a significantly high risk ratio for lung cancer. However, coal miners with short experience had no excess risk. This result could be due to chance, because the observed period was short and because few deaths from lung cancer were expected among coal miners with short experience. Japanese researchers ${ }^{1,4-6)}$ have previously reported that pneumoconiosis patients and workers exposed to dust showed between 2.7-fold and 4.1-fold excess mortality from lung cancer, higher figures than in our study. None of these studies took the effect of smoking into account and all included numerous compensated pneumoconiosis patients as subjects. Workers exposed to dust reportedly tend to smoke more than the general population ${ }^{2,7)}$, and the risk of smoking for lung cancer has been found to be much higher than that of exposure to dust ${ }^{7}{ }^{9}$. These results were consistent with our study. With the decline in the Japanese coal industry from around 1960, coal miners left the mines to look for other work or to live on welfare benefits; all coal mines in the study area had shut down by 1973. Although we had little information on the work histories of the coal miners after leaving the mines, there are very few hazardous jobs involving exposure to carcinogens in the study area. It has been reported that the association between exposure to dust and lung cancer may also be influenced by other factors such as radon daughters and polycyclic aromatic hydrocarbons $^{2,3,7,9-11)}$. Although data on these factors were not available in our study, there are no reports indicating that coal mines in the study area had elevated radon daughter concentrations. British researchers ${ }^{16,17)}$ have found no increased risk of lung cancer among coal miners. One possible explanation is that the respirable dust in British coal mines contains low levels of free silica ${ }^{9,16)}$. Japanese coal miners are thus exposed to higher levels of free silica than British miners.

The relationship between exposure to dust and mortality from all malignant neoplasms is controversial ${ }^{1-5,7,8,12,14)}$. Some studies have found no excess neoplasmrelated mortality among silicosis patients and workers exposed to dust $\mathrm{t}^{1,3,4,8,12)}$. It may be that high mortality from pulmonary tuberculosis, pneumoconiosis and other respiratory diseases competes with cancer mortality, meaning that patients with severe silicosis could die prematurely from pulmonary tuberculosis, pneumoconiosis and other respiratory diseases before any cancer occurs. On the other hand, Finkelstein et $a .^{2)}$ and Zambon et al. ${ }^{7)}$ have reported that silicosis patients had significant excess mortality from all malignant neoplasms. In our study, coal miners had a significantly high risk ratio for all malignant neoplasms because they had excess risk for stomach cancer, liver cancer and lung cancer, though not at statistically significant levels. Stomach cancer, liver cancer and lung cancer are the three leading causes of cancer death in male Japanese. A dose-response relationship was also found between risk ratios for all malignant neoplasms and the length of experience in coal mining. Ebihara et al. ${ }^{1,18)}$ indicated that pneumoconiosis 
patients had immunological abnormality and suggested that this may predispose pneumoconiosis patients to the development of malignancies of various organs. An association between coal mining and stomach cancer has been found in some epidemiological studies ${ }^{2,19)}$. However, diet is closely related to stomach cancer ${ }^{20)}$, and hepatitis B virus (HBV) and hepatitis C virus (HCV) infections are major causes of liver cancer. One study showed that $86.2 \%$ of hepatocellular carcinoma patients were hepatitis B surface antigen positive or hepatitis C virus antibody positive ${ }^{21)}$. In our study, risk ratios were calculated without adjusting for these confounding factors; although blood transfusion was adjusted for, HBV and HCV infections were not (risk ratio of blood transfusion for liver cancer $=5.0, p<0.001$ ). Therefore, it is possible that these confounding factors contribute to the increased risks observed for stomach cancer and liver cancer. SMRs for liver cancer were significantly high among both coal miners and non-coal-miners. This reflects a geographical variation in mortality from liver cancer. Mortality from liver cancer in the study area was much higher than that in Japan overall ${ }^{22}$. Also, prevalence of HBs antigen positive and HCV antibody positive among blood donors was higher in the study area than in other areas, according to the data from the Japanese Red Cross ${ }^{23)}$.

\section{REFERENCES}

1) Ebihara I, Shinokawa E, Kawami M, Kurosawa T. Systemic diseases caused by exposure to mineral dust: A prospective cohort mortality study of pneumoconiosis patients in Japan. J Science Labour 1990; 66: 301-15 (in Japanese).

2) Finkelstein M, Liss GM, Krammer F, Kusiak RA. Mortality among workers receiving compensation awards for silicosis in Ontario 1940-85. Brit J Ind Med 1987; 44: 588-94.

3) Forastiere F, Lagorio S, Michelozzi P, Perucci CA, Axelson O. Mortality pattern of silicotic subjects in the Latium region, Italy. Brit J Ind Med 1989; 46: 877-80.

4) Shima S, Arakawa T, Kato Y, Yoshida T, Taniwaki H, Nagaoka K, Nishida Y, Otani N. Epidemiological studies on the risk of pulmonary tuberculosis or lung cancer in ceramic workers with pneumoconiosis. J Science Labour 1991; 67: 565-71 (in Japanese).

5) Ebihara I. A retrospective cohort mortality study of copper miners. J Science Labour 1991; 67: 93-101 (in Japanese).

6) Chiyotani K. Studies on the association between pneumoconiosis and lung cancer. Jpn J Traumatol Occup Med 1987; 35: 554-61 (in Japanese).

7) Zambon P, Simonato L, Mastrangelo G, Winkelmann R, Saia B, Crepet M. Mortality of workers compensated for silicosis during the period 1959-1963 in the Veneto region of Italy. Scand J Work Environ Health 1987; 13: 118-23.

8) Koskela RS, Klockars M, Jarvinen E, Kolari P, Rossi A. Mortality and disability among granite workers. Scand J Work Environ Health 1987; 13: 18-25.

9) Carta P, Cocco PL, Casula D. Mortality from lung cancer among Sardinian patients with silicosis. Brit J Ind Med 1991; 48: 122-9.

10) Hnizdo E, Sluis-Cremer GK. Silica exposure, silicosis, and lung cancer: a mortality study of South African gold miners. Brit J Ind Med 1991; 48: 53-60.

11) Amandus H, Costello J. Silicosis and lung cancer in U.S. metal miners. Arch Environ Health 1991; 46: 82-9.

12) Chen J, McLaughlin JK, Zhang JY, Stone BJ, Luo J, Chen R, Dosemeci M, Rexing SH, Wu Z, Hearl FJ McCawley MA, Blot WJ. Mortality among dust-exposed Chinese mine and pottery workers. J Occup Med 1992; 34: 311-6. 
13) Tanaka S, Naruo Y, Toyofuku T. Silicosis and silicotuberculosis in a coalmine. Jpn J Ind Health 1960; 2: 622-8 (in Japanese).

14) Sherson D, Svane O, Lynge E. Cancer incidence among foundry workers in Denmark. Arch Environ Health 1991; 46: 75-81.

15) Guenel P, Hojberg G, Lynge E. Cancer incidence among Danish stone workers. Scand J Work Environ Health 1989; 15: 265-70.

16) Miller BG, Jacobsen M. Dust exposure, pneumoconiosis, and mortality of coalminers. Brit J Ind Med 1985; 42: 723-33.

17) Rooke GB, Ward FG, Dempsey AN, Dowler JB, Whitaker CJ. Carcinoma of the lung in Lancashire coalminers. Thorax 1979; 34: 229-33.

18) Ebihara I, Kawami M, Kawami M, Shinokawa E. An epidemiological study on immunological abnormalities among workers exposed to dust. J Science Labour 1986; 62: 325-52 (in Japanese).

19) Matolo NM, Klauber MR, Gorishek WM, Dixon JA. High incidence of gastric carcinoma in a coal mining region. Cancer 1972; 29: 733-7.

20) Wynder EL, Gori GB. Contribution of the environment to cancer incidence: An epidemiologic exercise. J Natl Cancer Inst 1977; 58: 825-32.

21) Hayashi J, Hirata M, Nakashima K, Noguchi A, Kashiwagi S, Matsui M, Ishibashi H, Maeda Y. Hepatitis $C$ virus is a more likely cause of chronic liver disease in the Japanese population than hepatitis B virus. Fukuoka Acta Med 1991; 82: 648-54.

22) Osajima K, Watanabe D, Une H, Esaki H, Shigematsu T. Studies on the geographical differences in mortality for selected causes of death in Fukuoka Prefecture, 1983-1987. III. Mortalities for cirrhosis and cancer of the liver. Med Bull Fukuoka Univ 1994; 21: 235-45 (in Japanese).

23) Yoshizawa H, Tanaka J, Ohhori K, Iizuka H, Tango T, Watanabe J, Aoyama K, Mizui M. Prevalence of the HCV associated markers among blood donors in Japan. Jpn J Clin Med 1991; 49: 357-65 (in Japanese). 